\title{
The effect of the climatic condition on the radiant asymmetry
}

\author{
Concettina Marino ${ }^{1}$, Pinky Misiani ${ }^{2}$, Antonino Nucara ${ }^{1}$, Matilde Pietrafesa ${ }^{1 *}$ \\ ${ }^{1}$ Department of Civil, Energy, Environmental and Material Engineering (DICEAM), \\ "Mediterranea" University of Reggio Calabria, Via Graziella - Feo di Vito, Reggio Calabria \\ 89122 , Italy \\ ${ }^{2}$ Department of Environment, Land and Infrastructure Engineering (DIATI), Polytechnic of \\ Torino, Corso Duca degli Abruzzi 24, Torino 10129, Italy
}

Email: matilde.pietrafesa@unirc.it

\begin{abstract}
This paper analyzes the influence of solar radiation, considering both its direct and diffuse component, on the local thermal comfort of subjects in indoor environments. In fact, as well as too hot or too cold climatic conditions may cause global thermal discomfort, an unwanted cooling or heating of a particular confined area of the body may cause local thermal discomfort, which may occur for vertical air temperature differences, unsuitable temperatures of the floor, drafts and radiant asymmetries. In this context, this work is focused on radiant asymmetry issues and it aims to analyze the radiant asymmetry dependence on outdoor climate parameters, with special regard to the solar radiation. To this purpose, a specific experimental campaign of measurements was conducted. The analysis of the results shows that the solar radiation alters the radiant field and produces a high radiant asymmetry in correspondence of the points of the environment directly irradiated by sunrays.
\end{abstract}

Keywords: Local Discomfort, Radiant Asymmetry, Solar Radiation.

\section{INTRODUCTION}

Nowadays, the level of the quality of life in indoor environment increasingly requires high standards, which lead towards an extremely precise definition of the requisites which ensure conditions of thermal comfort in the spaces where people live and work or in particular spaces as, for example, the operating rooms [1]; these needs may involve impacts on building energy consumptions which must be taken into account [2].

Too hot or too cold climatic conditions may cause human body discomfort as a whole: in this case, this occurrence is referred to as "Global thermal discomfort". It can be assessed using the average values of the microclimatic variables and Fanger's PMV and PPD indexes, described in the ISO 7730 standard [3] and based on the ASHRAE thermal sensation scale [4].

Nevertheless, an unwanted local cooling or heating of a particular area of the body may also cause thermal discomfort: in this case, "Local thermal discomfort" occurs and it is evaluated assessing, at each involved point of the environment, the needed microclimatic parameters [5].

Therefore, for a proper evaluation of indoor comfort conditions, the estimation of the average values of the environmental variables does not suffice; on the contrary, the assessment of the involved environmental parameters in correspondence of various points of the same environment is required, in order to highlight any possible spatial variability, which can be potentially accountable for local discomfort conditions $[6,7]$.

In this regard, the outdoor climatic parameters play a pivotal role in the variability of the indoor conditions. In fact, the outdoor temperature modifies the indoor air temperature and the indoor surface temperatures of the building envelope elements, producing effects on the convective and radiative exchanges. The presence of solar radiation, with its direct and diffuse components, dramatically alters the radiant field and may lead to intolerable local climatic conditions [8]. Moreover, because of the fact that the outdoor conditions vary over time, the indoor climatic conditions are also variable with both time and space.

Among the main causes of local discomfort, which are vertical air temperature differences, unsuitable temperatures of the floor, drafts and radiant asymmetries, in this work, the influence of the outdoor climate parameters on the radiant asymmetry has been analyzed.

To this aim, a specific experimental campaign of measurements was performed; a microclimatic analyzer was used for the measurements carried out in the studied indoor environment, whereas a weather station was utilized for the measurements in the outdoor environment. 
The acquisition of the microclimatic parameters has been accomplished following the indications reported in the ISO 7726 Standard [9], regarding both the technical characteristics of the probes and the measurement procedures.

\section{DETERMINATION OF THE PLANE RADIANT TEMPERATURE}

A subject placed in a thermal environment may be exposed to asymmetric thermal radiation, due to the spatial inhomogeneity of the radiant field.

To evaluate the radiant asymmetry, a specific parameter has been introduced, namely the asymmetry of the radiant temperature, which is the difference between the plane radiant temperatures evaluated in two opposite directions [9].

The plane radiant temperature, in turn, is defined as the uniform temperature of an enclosure where the radiative flux on one side of a small plane element, the so called "test area", is the same as in the actual environment [10].

\subsection{Evaluation methods}

The international standard ISO 7726 [9] provides several methods to measure and to calculate the physical quantities characterizing the environmental conditions of a living space. Moreover, it specifies the minimum characteristic of the measure instruments.

As far as the plane radiant temperature is concerned, the standard provides various measurement and calculation methods.

Among the measurement methods, the standard describes methodologies which utilize the following sensors:

- the heat sensor consisting of a reflective disc and an absorbing disk;

- the constant air temperature disk;

- the net radiometer.

Because the net radiometer allows also the direct determination of the radiant temperature asymmetry, this method has been used in this study.

A net radiometer consists of a small black surface and a thermopile, placed between the sides of the probe. The net heat flow between the two sides is equal to difference between the radiant heat flow transfers by each side of the probe.

The evaluation of the radiant temperature asymmetry with the net radiometer is obtained from the measure of the net radiation on a side of the probe, $P$. Therefore, the asymmetry is calculated starting by the following equation:

$P=4 \sigma T_{n}^{3}\left(T_{p r 1}-T_{p r 2}\right)$

where:

- $P$ is the measured radiation, $\mathrm{Wm}^{-2}$;

- $\sigma$ is the Stefan-Boltzmann constant, $\mathrm{Wm}^{-2} \mathrm{~K}^{-4}$;

- $T_{n}$ is the temperature of the net radiometer, $\mathrm{K}$;

- $T_{p r 1}$ and $T_{p r 2}$ are the plane radiant temperature in the two opposite directions, $\mathrm{K}$;

Then, the radiant temperature asymmetry is obtained by the following equation:

$\Delta t_{p r}=T_{p r 1}-T_{p r 2}=\frac{P}{4 \sigma T_{n}^{3}}$
With regard to the calculation methods, the ISO 7726 reports an approach, which allows the assessment of the plane radiant temperature by knowing:

- the temperature of the surfaces of the environment;

- the angle factor between a small plane element, namely the "test area", and the surrounding surfaces, in turn calculated as a function of the geometrical configuration of each surface and of its distance from the "test area".

Because of the fact that most of the building materials is characterized by a high emissivity, it is possible to neglect the reflection of the incident radiant fluxes, so that all the involved surfaces are assumed to perform as black bodies.

Therefore, the plane radiant temperature can be calculated using the following equation:

$T_{p r}=\sqrt[4]{\sum_{i=1}^{N} T_{i}^{4} F_{T A \rightarrow i}}$

where:

- $T_{p r}$ is the plane radiant temperature, $\mathrm{K}$;

- $T_{i}$ is the ith surface temperature, $\mathrm{K}$;

- $F_{T A \rightarrow i}$ is the angle factor between the test area element and the $i^{\text {th }}$ surface;

- $N$ is the number of surface.

Although in indoor environments the calculation of the angle factors between the human body and the surfaces of the environment requires the acquaintance of the shape and the posture of the subject [11-14], on the contrary, angle factors between the test area and the same surfaces of the environment may be calculated by means of simpler equations.

As a matter of fact, in case of rectangular surfaces, considering the configurations reported in Figure 1 and Figure 2, the view factor $F_{T A \rightarrow i}$ can be estimated by means of the equations (3) and (4) respectively.

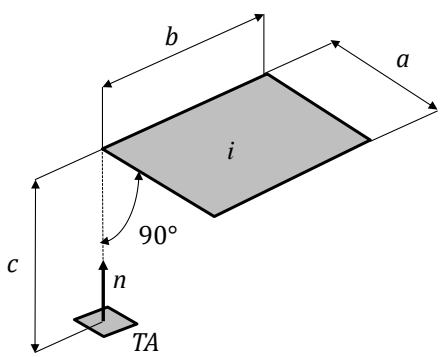

Figure 1. Plane element parallel to a rectangular surface

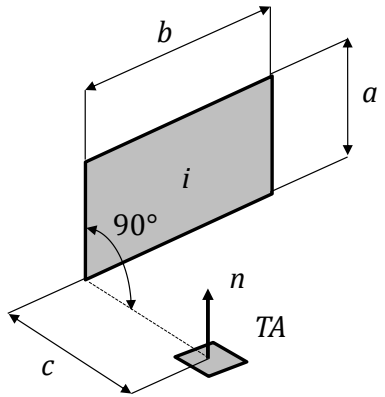

Figure 2. Plane element orthogonal to a rectangular surface

$F_{T A \rightarrow i}=\frac{1}{2 \pi}\left(\frac{X}{\sqrt{1+X^{2}}} \tan ^{-1} \frac{Y}{\sqrt{1+X^{2}}}+\frac{Y}{\sqrt{1+Y^{2}}} \tan ^{-1} \frac{X}{\sqrt{1+Y^{2}}}\right)$ 
with $X=a / c$ and $Y=b / c$.

$F_{T A \rightarrow i}=\frac{1}{2 \pi}\left(\tan ^{-1} \frac{1}{Y}-\frac{Y}{\sqrt{X^{2}+Y^{2}}} \tan ^{-1} \frac{Y 1}{\sqrt{X^{2}+Y^{2}}}\right)$

with $X=a / b$ and $Y=c / b$.

The radiant temperature asymmetry is hence calculated, by means of eq. (2), as the difference between the plane radiant temperatures in two opposite directions.

\subsection{Effect of the solar radiation}

The thermal comfort conditions in living and working environments can be strongly influenced by the presence of thermal radiation sources.

Solar radiation entering through glazed surfaces may alter radiant field and make it dramatically asymmetric. In fact, the solar rays may hit only a single face of the test area, while the opposite one will be in shadow.

Therefore, depending on the shading effect of the building envelope at the considered position, the influence of the solar radiation may be remarkable for a specific direction, but negligible for the opposite.

Moreover, diffuse and direct component of solar radiation may affect the main radiant temperature and the plane temperature asymmetry with different intensity [15-18], due to their different behavior inside indoor environment.

Consequently, the calculation of the plane radiant temperature should take these phenomena into account considering parameters referred to diffuse and direct solar radiation.

To this purpose the following equation may be utilized [19]:

$T_{p r}=\sqrt[4]{\sum_{i=1}^{N} T_{i}^{4} F_{T A \rightarrow i}+\frac{0.7}{\sigma}\left(I_{d} \sum_{j=1}^{M} F_{T A \rightarrow j}+I_{b \perp}\right)}$

where:

- $T_{p r}$ is the plane radiant temperature, $\mathrm{K}$;

- $T_{i}$ is the $i^{\text {th }}$ surface temperature, $\mathrm{K}$;

- $F_{T A \rightarrow i}$ is the angle factor between the test area and the $i^{\text {th }}$ surface;

- $N$ is the number of surfaces;

- $\sigma$ is the Stefan-Boltzmann constant, $\mathrm{Wm}^{-2} \mathrm{~K}^{-4}$;

- $I_{d}$ is the intensity of the diffuse solar radiation, $\mathrm{Wm}^{-2}$;

- $F_{T A \rightarrow j}$ is the angle factor between the test area element and the $j^{\text {th }}$ glazed surface;

- $M$ is the number of glazed surfaces;

- $I_{b \perp}$ is the component of the beam solar radiation perpendicular to the surface of the test area, $\mathrm{Wm}^{-2}$.

\section{EXPERIMENTAL EVALUATION OF THE RADIANT ASYMMETRY}

The maintenance of appropriate environmental quality levels in living spaces implies the accurate evaluation of several environmental variables [20-21].

In order to analyze the effect of outdoor meteorological parameters on indoor thermal conditions in confined environments, with particular reference to local discomfort produced by radiant asymmetry, an experimental measurement campaign in a room of the Mediterranean University of Reggio Calabria was performed.

\subsection{Description of the environment}

The studied environment is an office, located on the fifth floor of the main engineering block of the Mediterranean University of Reggio Calabria.

The room has a rectangular shape, with a glazed surface facing South, and it is separated from the adjacent office by a plasterboard wall structure used as a library. The furniture consists of a desk, three chairs and two libraries, in addition to a standard office equipment (PC, printer, etc.).

As regard to the HVAC system, the room equipment consists of an air terminal unit, which delivers the primary air from the single duct air loop, and a fan coil unit located under the window. However, the system was turned off during the measurement campaign.

The window is composed by an aluminum frame and a double pane clear glass structure with a thickness of the air chamber of $12 \mathrm{~mm}$; the door is made of honeycomb wood.

Dimensions and geometry of the environment are depicted in Figure 3.

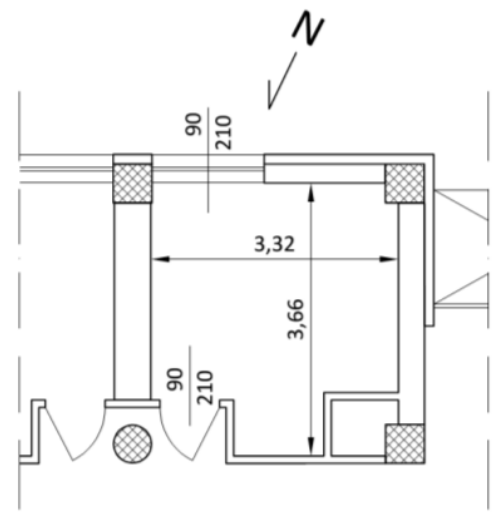

Figure 3. Sketch view of the environment

\subsection{Experimental apparatus}

Two typologies of apparatus were exploited during the experimental campaign:

- instruments for measuring microclimatic parameters in the indoor environment;

- instruments for measurement of meteorological parameters in the outdoor environment.

The utilized instrumentation is a part of the measurement equipment owned by the Laboratory of Energy and Environment of the Department of Civil, Energy, Environmental and Material Engineering of the Mediterranean University of Reggio Calabria.

\subsubsection{Indoor measurements}

With regard to the indoor measurements, the experimental apparatus is a monitoring system consisting of a set of probes measuring microclimatic parameters, connected to a programmable data-logger LSI-Lastem ELO 515 (Figure 4).

By means of a specific management software (Figure 5), the data-logger has been configured to acquire data at a definite time step. The connected probes, which have the technical characteristics reported in Table.1, are listed below:

- n. 1 thermohygrometer (DMA672.1);

- n. 2 globe-thermometer (EST131\#S); 
- n. 3 net radiometer (ESR\#231).

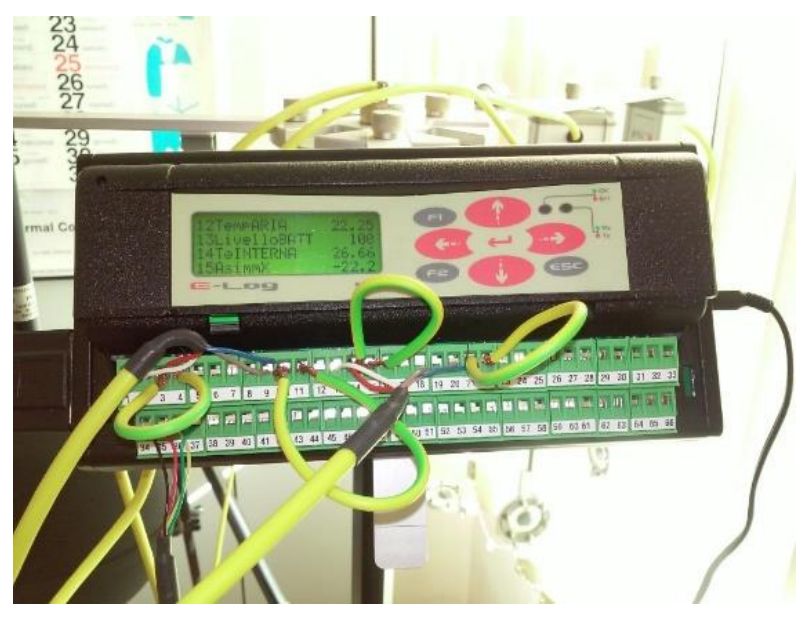

Figure 4. LSI-lastem data logger ELO515

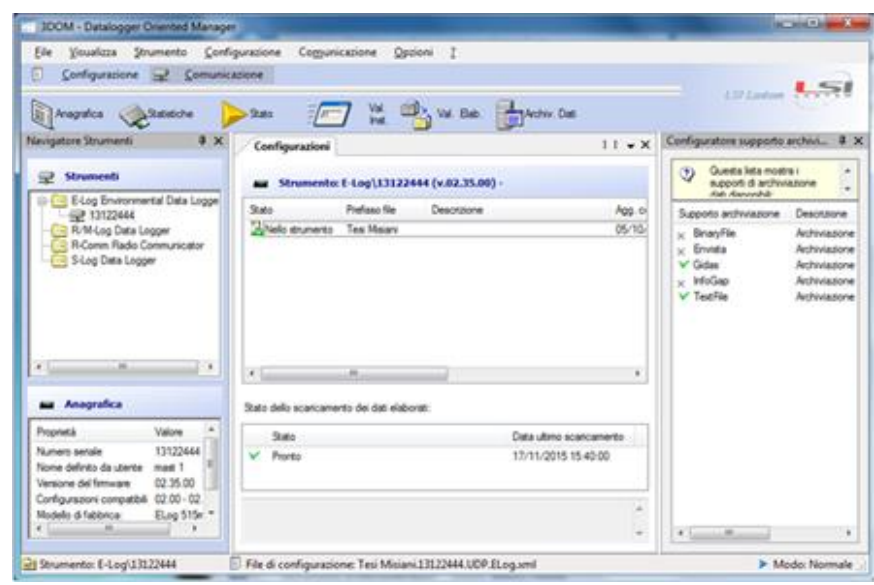

Figure 5. Management software of the data-logger LSILastem ELO 515.

Table.1. Technical characteristics of the probes

\begin{tabular}{cccc}
\hline Probe code & $\begin{array}{c}\text { Measured } \\
\text { parameter }\end{array}$ & $\begin{array}{c}\text { Measurement } \\
\text { range }\end{array}$ & Accuracy \\
\hline \multirow{2}{*}{ DMA672.1 } & Air temperature & $-50 \ldots+70^{\circ} \mathrm{C}$ & $\pm 0.1^{\circ} \mathrm{C}$ \\
\cline { 2 - 4 } & $\begin{array}{c}\text { Relative } \\
\text { Humidity }\end{array}$ & $0-100 \%$ & $\begin{array}{c} \pm 1.5 \% \\
\mathrm{RH}\end{array}$ \\
\hline \multirow{2}{*}{ EST131\#S } & $\begin{array}{c}\text { Globe } \\
\text { temperature }\end{array}$ & $-20 \ldots 60^{\circ} \mathrm{C}$ & $\pm 0.15^{\circ} \mathrm{C}$ \\
\hline \multirow{2}{*}{ ESR\#231 } & $\begin{array}{c}\text { Temperature } \\
\text { asymmetry }\end{array}$ & $\begin{array}{c}-1500 \ldots+1500 \\
\mathrm{~W} / \mathrm{m} 2\end{array}$ & $\pm 3 \%$ \\
\hline
\end{tabular}

\subsubsection{Outdoor measurements}

In the outdoor environment, the meteorological data were measured using the weather station Vaisala Weather Transmitter WXT520 (Figure 6), located on the roof of main building of the engineering block of the Mediterranean University of Reggio Calabria.

The weather station is linked through a LAN connection to a PC and is remotely controlled by means of a dedicated software (Figure 7), which allows the management of the instrumentation and the automatic data download. The technical characteristics of the apparatus are reported in Table 2.
Table 2. Technical characteristics of Vaisala WXT520

\begin{tabular}{lll}
\hline Measured parameter & Measurement range & Accuracy \\
\hline Air temperature & $-52 \ldots+60^{\circ} \mathrm{C}$ & $\pm 0.3^{\circ} \mathrm{C}$ \\
\hline Relative Humidity & $0-100 \%$ & $\pm 3 \% \mathrm{RH}$ \\
\hline Rain intensity & $0 \ldots 200 \mathrm{~mm} / \mathrm{h}$ & $\pm 0.1 \mathrm{~mm} / \mathrm{h}$ \\
\hline
\end{tabular}

Figure 6. Vaisala weather transmitter WXT520

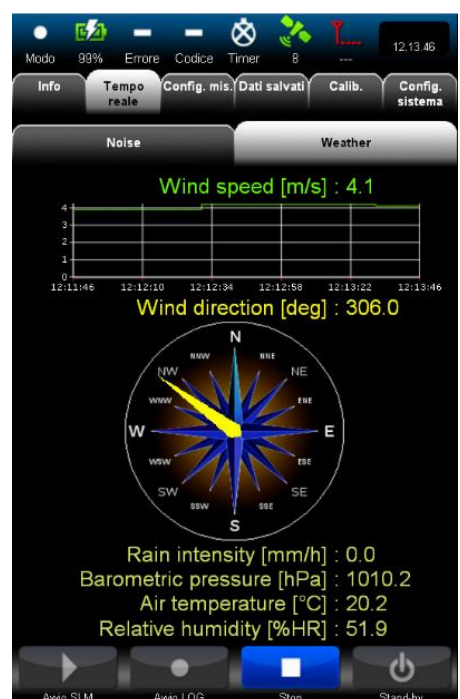

Figure 7. Management software of Vaisala weather transmitter WXT520

\subsection{Measurement campaign}

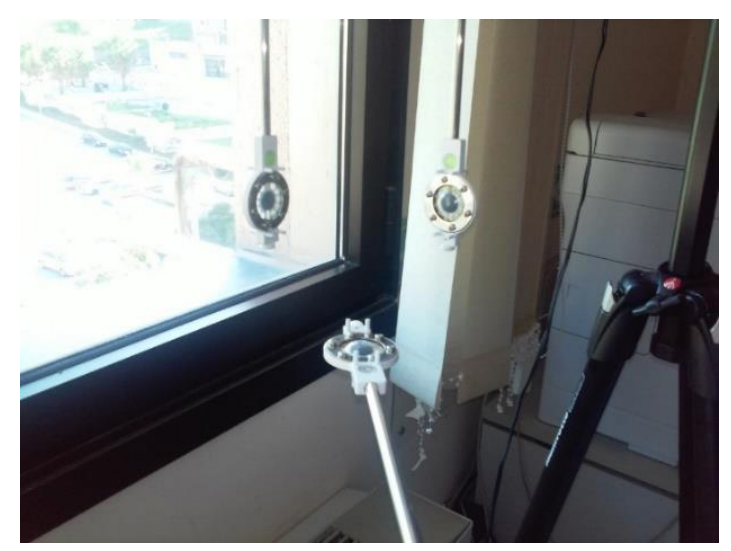

Figure 8. Disposition of radiometers

The measurement campaign was performed between October 6 and November 9, 2016. 
As far as the indoor measurements are concerned, the probes have been collocated at a height of 1.10 meters from the floor. In particular, the net radiometers were placed along a Cartesian tern, with the $\mathrm{X}$ axis oriented perpendicularly to the window, pointing South, at a distance of 1.00 meters from the glazed surface, the $\mathrm{Y}$ axis pointing West and the $\mathrm{Z}$ axis pointing to the floor (Figure 8).

The instruments were synchronized to measure, with a time steps of 10 minutes, the following parameters:

- air temperature;

- air humidity;

- globe temperature, in two position of the environment;

- radiant asymmetry, along the $\mathrm{X}, \mathrm{Y}$ and $\mathrm{Z}$ directions.

On the other hand, in outdoor environment, with the same time steps, the following variables were measured:

- air temperature;

- air humidity;

- rain intensity.

All the measured data were transferred to a PC and stored in ASCII format, at regular intervals. Then, they were processed and utilized to calculate some of the parameters not directly measurable with the probes.

\section{RESULTS OF THE MEASUREMENTS}

The following figures show the time trend of the measured parameters for the entire period between October 6 and November 8, 2016; in particular, Figure 9 and Figure 10 report the air temperature and relative humidity trends, in outdoor and indoor environment respectively.

Furthermore, in order to identify the rainy days, characterized by reduced solar gains, Figure 11 reports the rain intensity detected by means of the WXT520 weather station.

It is worthy of note that, during the analyzed period, the outdoor air temperature values range between 13.5 and $28.8^{\circ} \mathrm{C}$, while the indoor air temperature values range between 19.5 and $32.8^{\circ} \mathrm{C}$; the relative humidity range between 37 and $90 \%$ in outdoor environment and between 25 and $64 \%$ in indoor environment.

The indoor air temperature is always higher than the outdoor one. This is due to the absence of a working HVAC system during the measure period, to the internal and solar gains and, finally, to thermal inertia of the building envelope which is the cause that preserves the high values of the air temperature during nocturnal periods. This phenomenon is shown in Figure 12, where the measured outdoor and indoor air temperatures are simultaneously reported.

Having plotted temporal trends of the parameters for the entire measurement period, the analysis continued focusing on two particular days, characterized by opposite meteorological conditions: a sunny day and a rainy day when the direct component of solar radiation was totally negligible. The chosen sunny day, with no rain at all, was October $14^{\text {th }}$; whereas November $1^{\text {st }}$, is the selected rainy day during which the intensity of the rainfall was rather remarkable.

Figure 13 and Figure 14 report the air temperature of the outdoor and indoor environment, the globe temperature and the rainfall intensity for the two selected days.
It is worth noting that in the sunny day, owing to the effect of solar radiation between $11 \mathrm{a} . \mathrm{m}$. and 1 p.m., the globe temperature considerably increases and its values exceed the air temperature ones, with a maximum difference of $12^{\circ} \mathrm{C}$ at 11:30 a.m.; on the contrary, during the rainy day, the air and globe temperature show the same trends, so that, in this latter case, the indoor environment can be considered as thermally uniform.

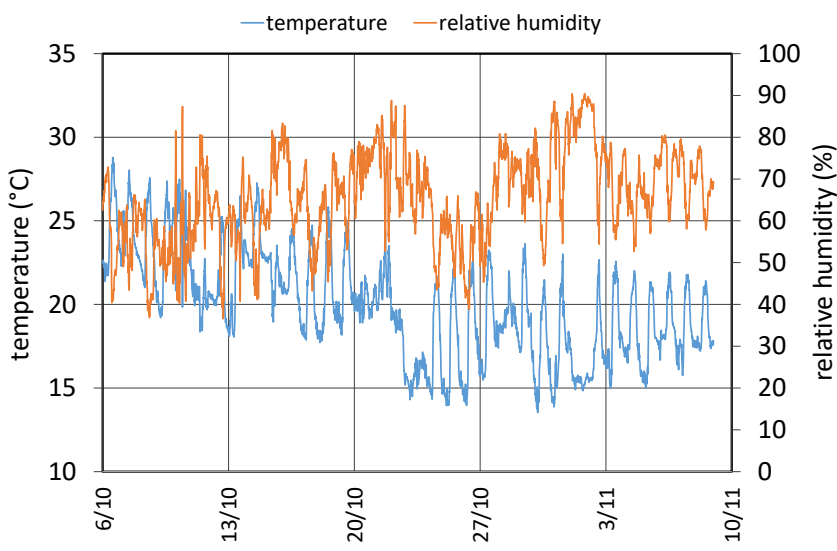

Figure 9. Air temperature and relative humidity in outdoor environment

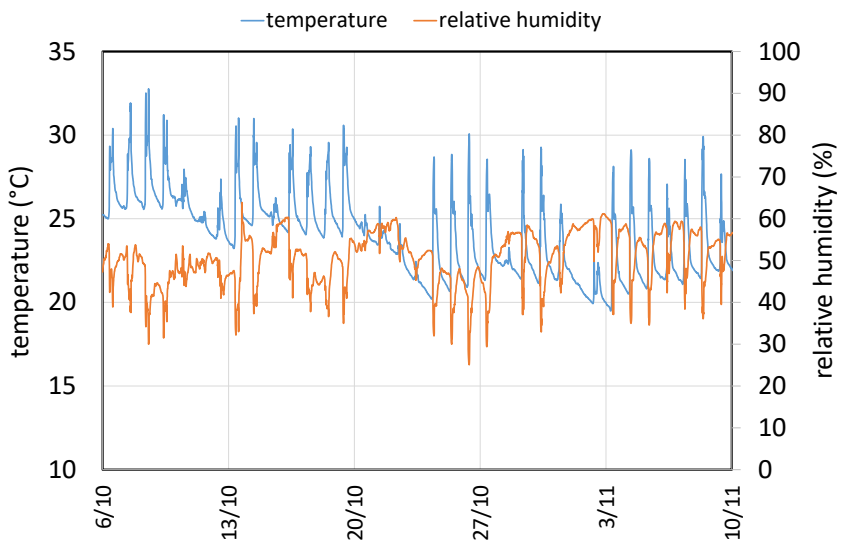

Figure 10. Air temperature and relative humidity in indoor environment

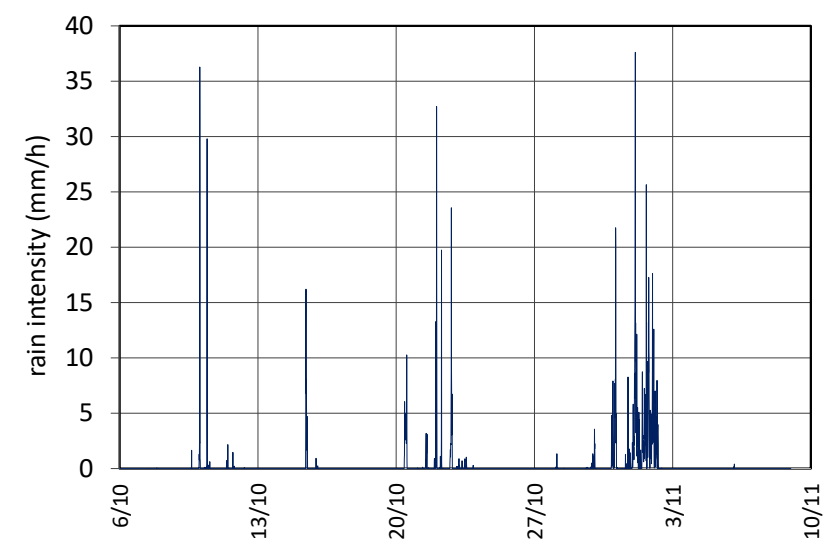

Figure 11. Rain intensity 


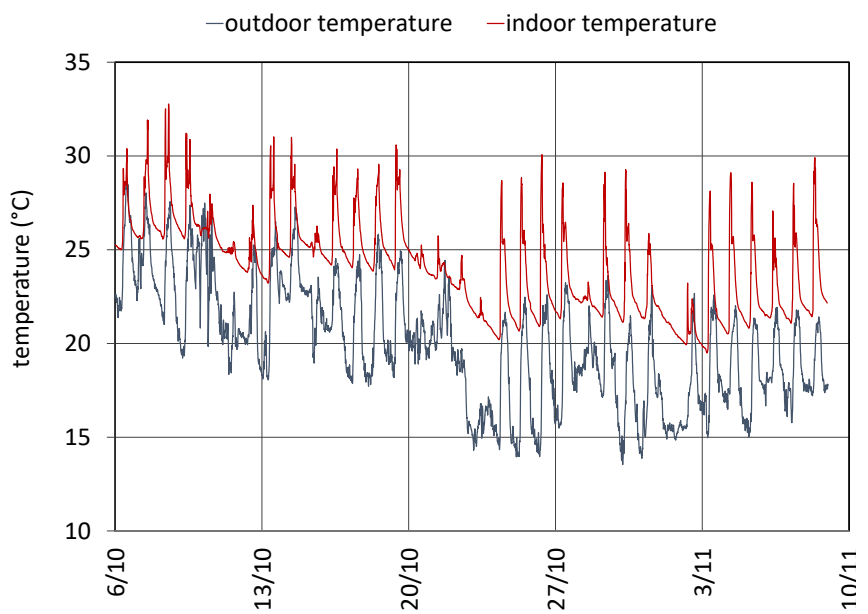

Figure 12. Indoor and outdoor air temperature

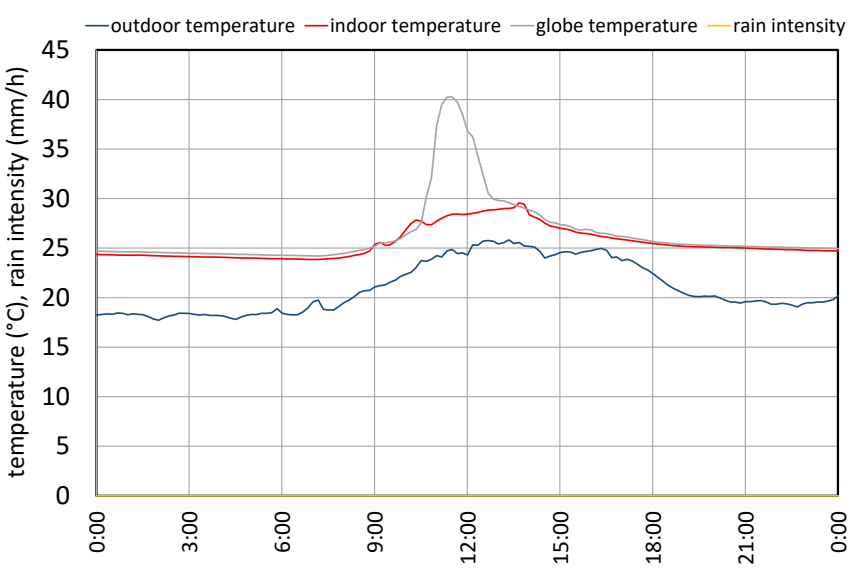

Figure 13. Indoor and outdoor air temperature, globe temperature and rain intensity (sunny day)

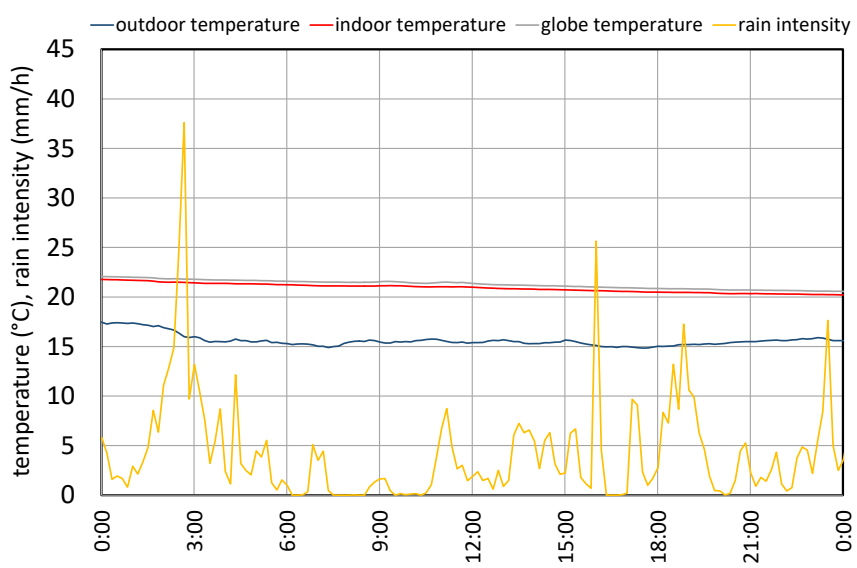

Figure 14. Indoor and outdoor air temperature, globe temperature and rain intensity (rainy day).

As a consequence, the former considerations lead to infer that solar radiation remarkably alters the radiant field inside the room; in order to assess the extent of this influence on local discomfort, the radiant asymmetries along the three directions $\mathrm{X}, \mathrm{Y}$ and $\mathrm{Z}$ were analyzed; the results of this analysis are reported in Figure 15 and Figure 16, for the sunny day and the rainy day respectively.

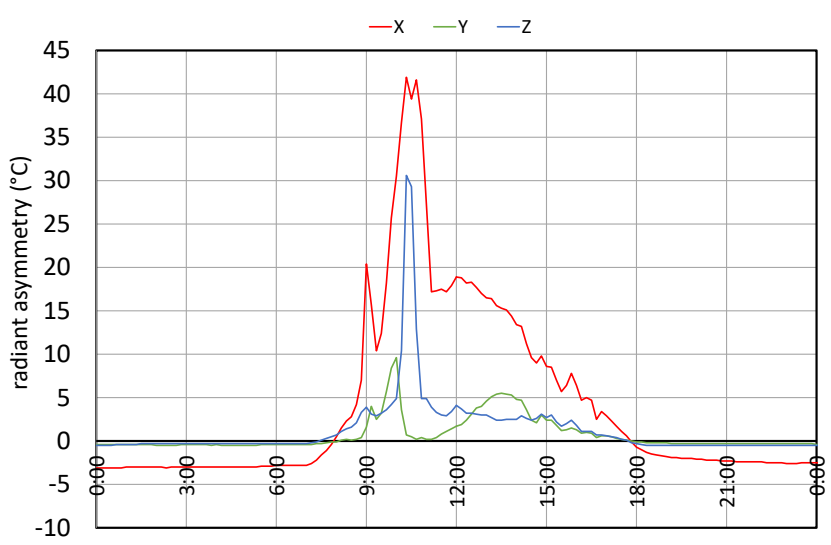

Figure 15. Radiant asymmetries (sunny day)

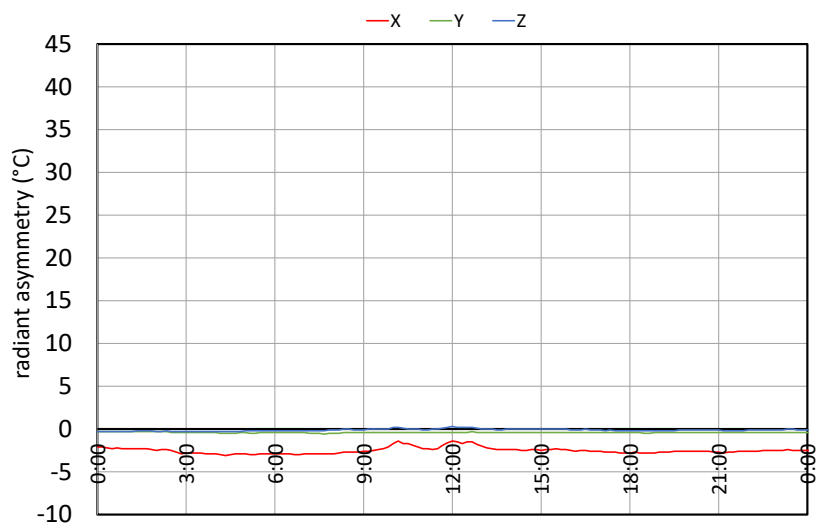

Figure 16. Radiant asymmetries (rainy day)

Table 3. Quality classes with regard to radiant asymmetry

\begin{tabular}{ccccc}
\hline \multirow{2}{*}{ Category } & \multicolumn{4}{c}{ Radiant asymmetry $\left({ }^{\circ} \mathrm{C}\right)$} \\
\cline { 2 - 5 } & Warm ceiling & Cold wall & Cold ceiling & Warm wall \\
\hline I & 5 & 10 & 14 & 23 \\
II & 6 & 12,5 & 16 & 29 \\
III & 7 & 13 & 18 & 35 \\
IV & $>7$ & $>13$ & $>18$ & $>35$ \\
\hline
\end{tabular}

It is possible to note that, in presence of solar radiation, the South facing glazed surface, as well as the South exposed external wall, behave as hot surfaces; as a matter of fact, the values of the asymmetry along $X$ direction are positive; the same phenomenon interests the $\mathrm{Y}$ and $\mathrm{Z}$ directions, where positive values of the asymmetry are also the proof of the influence of the sun irradiated window surface. In particular, it acts as a hot wall in the directions $\mathrm{X}$ and $\mathrm{Y}$ and as a hot ceiling in the Z-direction [22-23].

Conversely, during night time or in rainy days, the asymmetry along $\mathrm{X}$ direction assumes negative values so that the glazed surface may be deemed to perform as a cold vertical surface. On the other hand, the phenomenon is less noticeable along $\mathrm{Y}$ and $\mathrm{Z}$ directions where, without the effect of the sun, the radiant asymmetry assumes negative values close to zero, indicating that the glazed window slightly acts as a cold wall in the $\mathrm{Y}$ direction and as cold ceiling in the $\mathrm{Z}$ direction.

Moreover, the radiant asymmetry values in sunny days present large fluctuations over time, which rise above $40^{\circ} \mathrm{C}$ along the $\mathrm{X}$ direction and $30^{\circ} \mathrm{C}$ along the $\mathrm{Z}$ direction. 
With reference to the quality categories introduced by the EN 15251 Standard [24] and to asymmetry limits reported in the ISO 7730 Standard [3] (Table 3), it is inferred that the described conditions are unacceptable, since they belong to the IV quality category.

However, these values are achieved only in sunny days and, only for limited periods of the day, specifically when the beam solar component shines on the analyzed point within the indoor environment. On the contrary, in rainy days or during nighttime the radiant asymmetry values do not show appreciable variations.

Therefore, it is possible to assume that, although the radiant asymmetry reaches unacceptable values when the subject is directly hit by solar radiation, from a long-term point of view, this condition might have limited effects.

Therefore, it would be worthwhile to carry out further analysis, utilizing for example long-term indices [24-25], to evaluate the effect of weather conditions on a longer time period.

\section{CONCLUSIONS}

Solar radiation plays a pivotal role in environmental quality of buildings because it affects the radiant field of indoor environments. Therefore, it can greatly affect the comfort conditions, in terms of both global comfort and local discomfort.

In order to investigate on the effect of the solar radiation on the radiant field and on the local discomfort, in this research an experimental measure campaign was conducted. The aim was the assessment of the radiant temperature asymmetry and of its variations over time in an indoor environment.

The analysis was carried out in an office of the engineering block of the Mediterranean University of Reggio Calabria, during different external climate conditions, characterized by both sunny and rainy weather. The indoor parameters were measured by means of a microclimatic instrumentation, whereas a meteorological station was used for the measure of the outdoor parameters.

The results of the analysis show that in presence of solar radiation, glazed surface behaves as hot surface whereas, during nighttime or in rainy days, it behaves like a cold surface.

As a consequence, in sunny days, the values of radiant asymmetry denote high temporal variations and, in the sunny hours, they increase over $40^{\circ} \mathrm{C}$ for the asymmetry in horizontal direction and of about $30^{\circ} \mathrm{C}$ for the asymmetry in vertical direction. These conditions result unacceptable and out of the target limits reported in ISO 7730 standard, even though they occur only for short periods of time during the studied day. Conversely, during rainy days or nighttime, the radiant asymmetry values are close to zero and almost constants.

In conclusion, the presence of solar radiation significantly alters the radiant field in indoor environments. However this happens only for limited periods of time during a day, and precisely when the solar beam directly shines on the studied points within the indoor environment. On the contrary, during rainy days or nighttime periods, the radiant asymmetry values do not show appreciable variations.

\section{REFERENCES}

[1] Cannistraro G. (2016). Hypothermia Risk, Monitoring and Environment Control in Operating Rooms, Int. J. Heat Technol., Vol. 34, No. 2, pp. 165-171. DOI: 10.18280/ijht.340202

[2] Marino C., Nucara A., Peri G., Pietrafesa M., Pudano A., Rizzo G. (2015). A MAS-based subjective model for indoor adaptive thermal comfort, Sci. Technol. Built Environ., Vol. 21, No. 2, pp. 114-125. DOI: $10.1080 / 10789669.2014 .980683$

[3] ISO Ergonomics of the thermal environment Analytical determination and interpretation of thermal comfort using calculation of the PMV and PPD indices and local thermal comfort criteria (2005). ISO 7730, Geneva, Switzerland.

[4] ANSI/ASHRAE Thermal Environmental Conditions for Human Occupancy (2010). ANSI/ASHRAE Standard 55, Atlanta, GA.

[5] Rizzo G., Beccali M., Nucara A. (2004). Thermal Comfort, Encycl. Energy. pp. 55-64.

[6] Cannistraro G., Cannistraro M., Restivo R. (2015). Some observations on the radiative exchanges influence on thermal comfort in rectangular open-space environments, Int. J. Heat Technol., Vol. 33, No. 2, pp. 79-84. DOI: $10.18280 /$ ijht.330213

[7] Cannistraro G., Cannistraro M., Restivo R. (2015). The local media radiant temperature for the calculation of comfort in areas characterized by radiant surfaces, Int. J. Heat Technol., Vol. 33, No. 1, pp. 115-122.

[8] Marino C., Nucara A., Pietrafesa M. (2015). Mapping of the indoor comfort conditions considering the effect of solar radiation, Sol. Energy, Vol. 113, No. pp. 63-77. DOI: $10.1016 /$ j.solener.2014.12.020

[9] ISO Ergonomics of the thermal environment Instruments for measuring physical quantities(1998). ISO 7726, Geneva, Switzerland.

[10] EN ISO Ergonomics of the thermal environment Vocabulary and symbols (2001). EN ISO 13731, Geneva, Switzerland.

[11] Rizzo G., Cannistraro G., Franzitta G. (1992). Algorithms for the calculation of the view factors between persons and rectangular surfaces in parallelepiped environments, Energy Build., Vol. 19, No. pp. 51-60. DOI: 10.1016/0378-7788(92)90035-F

[12] Tanabe S.I., Narita C., Ozeki Y., Konishi M. (2000). Effective radiation area of human body calculated by a numerical simulation, Energy Build., Vol. 32, No. 2, pp. 205-215. DOI: 10.1016/S0378-7788(00)00045-1

[13] Calvino F., La Gennusa M., Nucara A., Rizzo G., Scaccianoce G. (2005). Evaluating human body area factors from digital images: A measurement tool for a better evaluation of the ergonomics of working places, Occup. Ergon., Vol. 5, No. 3, pp. 173-185.

[14] La Gennusa M., Nucara A., Pietrafesa M., Rizzo G., Scaccianoce G. (2008). Angle factors and projected area factors for comfort analysis of subjects in complex confined enclosures: Analytical relations and experimental results, Indoor Built Environ., Vol. 17, No. 4, pp. 346-360. DOI: 10.1177/1420326X08094621

[15] Marino C., Nucara A., Pietrafesa M., Polimeni E. (2017). The effect of the short wave radiation and its reflected components on the mean radiant temperature: modelling and preliminary experimental results, $J$. Build. Eng., Vol. 9, No. January 2017, pp. 42-51. DOI: 10.1016/j.jobe.2016.11.008

[16] La Gennusa M., Nucara A., Rizzo G., Scaccianoce G. 
(2005). The calculation of the mean radiant temperature of a subject exposed to the solar radiation-a generalised algorithm, Build. Environ., Vol. 40, No. 3, pp. 367-375. DOI: $10.1016 /$ j.buildenv.2004.06.019

[17] La Gennusa M., Nucara A., Pietrafesa M., Rizzo G. (2007). A model for managing and evaluating solar radiation for indoor thermal comfort, Sol. Energy, Vol. 81, No. 5, pp. 594-606. DOI: 10.1016/j.solener.2006.09.005

[18] Ali-Toudert F., Mayer H. (2006). Numerical study on the effects of aspect ratio and orientation of an urban street canyon on outdoor thermal comfort in hot and dry climate, Build. Environ., Vol. 41, No. 2, pp. 94-108. DOI: $\underline{10.1016 / \text { j.buildenv.2005.01.013 }}$

[19] Marino C., Nucara A., Pietrafesa M. (2017). Thermal comfort in indoor environment: Effect of the solar radiation on the radiant temperature asymmetry, Sol. Energy, Vol. 144, No. March 2017, pp. 295-309. DOI: 10.1016/i.solener.2017.01.014

[20] d'Ambrosio Alfano F.R., Dell'Isola M., Palella B.I., Riccio G., Russi A. (2013). On the measurement of the mean radiant temperature and its influence on the indoor thermal environment assessment, Build. Environ., Vol. 63, No. pp. 79-88. DOI: 10.1016/j.buildenv.2013.01.026

[21] Dell'Isola M., Frattolillo A., Palella B.I., Riccio G. (2012). Influence of measurement uncertainties on the thermal environment assessment, Int. J. Thermophys., Vol. 33, No. 8-9, pp. 1616-1632. DOI: $10.1007 / \mathrm{s} 10765-$ $\underline{012-1228-7}$

[22] Fontana L. (2010). Experimental study on the globe thermometer behaviour in conditions of asymmetry of the radiant temperature, Appl. Therm. Eng., Vol. 30, No. 6-7, pp. 732-740. DOI: 10.1016/i.applthermaleng.2009.12.003

[23] Hodder S.G., Loveday D.L., Parsons K.C., Taki A.H.

(1998). Thermal comfort in chilled ceiling and displacement ventilation environments: Vertical radiant temperature asymmetry effects, Energy Build., Vol. 27, No. pp. 167-173. DOI: 10.1016/S0378-7788(97)00038$\underline{8}$

[24] CEN Indoor environmental input parameters for design and assessment of energy performance of buildingsaddressing indoor air quality, thermal environment, lighting and acoustics (2007). EN 15251.

[25] Marino C., Nucara A., Pietrafesa M. (2012). Proposal of comfort classification indexes suitable for both single environments and whole buildings, Build. Environ., Vol. 57, No. December 2002, pp. 58-67. DOI: $\underline{10.1016 / \text { j.buildenv.2012.04.012 }}$

\section{NOMENCLATURE}

$P$
$T, t$
$\Delta t$
$F_{T A \rightarrow i}$
$I$

\section{Greek symbols}

$\sigma$

\section{Subscripts}

pr

$T A$

$d$

$b$

$\perp$ measured radiation, $\mathrm{Wm}^{-2}$

temperature, $\mathrm{K},{ }^{\circ} \mathrm{C}$

temperature asymmetry, ${ }^{\circ} \mathrm{C}$

angle factor

intensity of the solar radiation, $\mathrm{Wm}^{-2}$

Stefan-Boltzmann constant, $\mathrm{Wm}^{-2} \mathrm{~K}^{-4}$

plane radiant

net radiometer

test area

diffuse

beam

perpendicular 